\title{
Ant community structure on a small Pacific island: only one native species living with the invaders
}

\author{
Xim Cerdá · Elena Angulo · Stéphane Caut · \\ Franck Courchamp
}

\begin{abstract}
In most studies about ant communities, species are grouped into competitive hierarchies where top dominants drive the majority of other species away from resources. Nevertheless, in some ecosystems high ground temperatures may disrupt this hierarchical organization. Other changes in community structure are caused by the arrival of invasive ant species, which rapidly disassemble local communities. We studied the effects of competition and temperature on ant community organization on Surprise Island (New Caledonia). Four different habitats were distinguished: a central plain, a sea shore Argusia shrubland, a dense Scaveola shrub, and an arboreal Pisonia strata. Eight ant species were identified from pitfall traps (seven introduced and only one native species, Pheidole oceanica). Ant assemblages in each habitat had a different
\end{abstract}

Elena Angulo and Stéphane Caut have contributed equally.

Electronic supplementary material The online version of this article (doi:10.1007/s10530-011-0065-0) contains supplementary material, which is available to authorized users.

X. Cerdá (\&) · E. Angulo · S. Caut

Estación Biológica de Doñana, Consejo Superior de Investigaciones Científicas, Avda Americo Vespucio, 41092 Sevilla, Spain

e-mail: xim@ebd.csic.es

F. Courchamp

Lab. Écologie, Systematique and Evolution

(UMR CNRS 8074), Bât. 362, Université Paris Sud 11, 91405 Orsay Cedex, France ecologically dominant species, and a dominant species in one habitat could be non-dominant and less abundant in another. From interactions at baits, we built a competitive hierarchy where the top dominant species was the native Ph. oceanica. Daily foraging activity rhythms of the different species mostly overlapped. The relationship between bait occupation and ground temperature followed a negative linear pattern at all sites and for most species, except for the relatively thermophilous Monomorium floricola. Indices of co-occurrence in pitfall traps indicated that species co-occurred randomly with respect to one another. Conversely, species appeared to be segregated when we examined co-occurrence at baits at the sites where $\mathrm{Ph}$. oceanica was abundant. Oceanic islands are very susceptible to alien species, but on Surprise Island it seems that the sole native species dominates in some habitats when confronted by invasive species.

Keywords Exotic species - Biotic resistance · C-score $\cdot$ Formicidae $\cdot$ Pheidole oceanica . Surprise Island

\section{Introduction}

Oceanic islands may be regarded both as open sky laboratories for studying biological attributes of species (Brandao and Paiva 1994), and as model systems for understanding how biological invasions affect community structure and ecosystem function 
(O'Dowd et al. 2003). Many examples illustrate the impact of alien arthropods on native arthropods on oceanic islands (Gillespie and Roderick 2002); indeed, the success of alien species on oceanic islands is considered one of the classic observed patterns in ecology (Herben 2005 and references therein). Ants are among the most studied animals from island ecosystems and have frequently been model organisms in developing current ecological theory (MacArthur and Wilson 1967; Simberloff 1969, 1976; Herben 2005). Before human intervention, ants were relatively poor dispersers across oceanic islands, but they have evidently been introduced by human travel from native ranges scattered throughout the Old and New Worlds (Suarez et al. 2005; Ingram et al. 2006). Because of their great success and ecological dominance, ants are also among the worst invasive species, being particularly harmful in the island ecosystems (see examples in Kenis et al. 2009). Pacific archipelagoes abound with ants of many species, but most of them have evidently been introduced by humans (Wilson and Taylor 1967a; Lester et al. 2009; Rizali et al. 2010) and are tramp species according to Passera's (1994) criterion: i.e., they are invasive species with a worldwide distribution, small worker size, polygyny, omnivory, and unicoloniality. A potential factor that facilitates the invasion of oceanic islands is that many of these tramp species can survive in very marginal or highly disturbed habitats, and so can exist on relatively small islands (Morrison 1996a, b).

Invasive ant species pose serious threats to community structure and ecosystem function worldwide, not only because they reduce biodiversity but also because they rapidly disassemble communities and, as a result, alter community organization among the species that persist (Sanders et al. 2003). While many recent studies focus on how biodiversity may influence susceptibility to invasion, much less attention has been given to the importance of abiotic suitability. At small spatial scales, abiotic variability seldom receives attention as a factor influencing the community's vulnerability to invasion (Holway et al. 2002a; Menke and Holway 2006). This seems surprising given that abiotic heterogeneity and species-level differences in environmental tolerances are often emphasized as factors promoting coexistence among interspecific competitors (Cerdá et al. 1997, 1998; Chesson and Huntly 1997; Menke and Holway 2006; Wittman et al. 2010). Interspecific competition has long occupied a pre-eminent position among factors affecting composition and diversity of natural ant communities (Fellers 1987; Andersen 1992; Cerdá et al. 1997; but see Ribas and Schoereder 2002; Andersen 2008). In very dissimilar environmental conditions throughout different regions of the world, strongly competitive ants behave similarly by excluding other potential competitors from their territory and reducing the foraging success of subordinate species (Savolainen et al. 1989; Andersen 1992; Bestelmeyer 2000; Lester et al. 2010). Otherwise, communities in different regions would vary in the extent to which specific invasive species establish, because of disparities in the competitive ability of their constituent species (Thomas and Holway 2005). However, few ecological studies have attempted to test how the competitive ability of the resident biota might interact with abiotic suitability to affect invasion success (but see Holway et al. 2002a; Thomas and Holway 2005; Menke and Holway 2006; Menke et al. 2007).

The main objective of this study was to understand the patterns of community organization on a very small Pacific island (Surprise Island, New Caledonia) and how this structure could be affected by competition or abiotic environment (temperature). The previous history of ant communities on Surprise Island is unknown, and we aimed to capture an ecological snapshot of these communities. Surprise Island is an ideal location for this work because all but one of the species are exotic, and, owing to its small size, we could complete sample both the ant assemblages and the entire environmental spectrum. The specific objectives of this study were (1) to identify ant assemblages and to estimate the importance of native and exotic species in the different habitats; (2) to analyze the effects of temperature on foraging ecology of the different ant species in these environments; (3) to test how temperature (abiotic factor) and competition (biotic factor) affected the ant community structure on Surprise Island, and whether temperature influenced the outcome of interspecific interactions.

Materials and methods

Study area

Surprise Island is an uninhabited coral atoll of 24 ha (400 $9800 \mathrm{~m}$ ) belonging to the archipelago of 
Entrecasteaux reef. It is situated in the Pacific Ocean 130 miles $(230 \mathrm{~km})$ off the northern part of New Caledonia mainland “Grande-Terre" (Fig. 1). The climate is tropical, tempered by trade winds. Mean temperature is $25.8^{\circ} \mathrm{C}$ with a minimum in August $\left(16.4^{\circ} \mathrm{C}\right)$ and a maximum in February $\left(35.2^{\circ} \mathrm{C}\right)$. Average annual rainfall is $750 \mathrm{~mm}$, with a minimum in September and a maximum in March (CTRDP 1987).

Four distinct vegetation zones can be distinguished on Surprise Island (Fig. 1 and Electronic Supplementary Material Fig. ESM_1): (1) a ring of shrubs around the island with two dominant species, Argusia argentea and Suriana maritima of 1-3 m height (Argusia or ARG hereafter); (2) an arboreal strata with one tree species, Pisonia grandis, of 3-10 m height (Pisonia or PIS); (3) a dense monospecific patch with the bushy shrub Scaevola sericea of 1-3 m height (Scaevola or SCA); and (4) a central plain with different short plant species (e.g. Graminae, Compositae, Portulaceae) (La Plaine or LP). More details about vegetation can be found in Caut and Angulo (2009).

In 2003, a preliminary survey of ant species was carried out to identify ant species and their abundances in each habitat with extensive pitfall sampling throughout the island (see methods in Caut and Angulo 2009). This allowed one representative plot of $30930 \mathrm{~m}$ to be chosen in each habitat, to study ant communities (Fig. 1).

Pitfall trapping methods

The remoteness of the island, the difficult sea conditions during much of the year (i.e., cyclones), and the difficulties in transporting water, food and

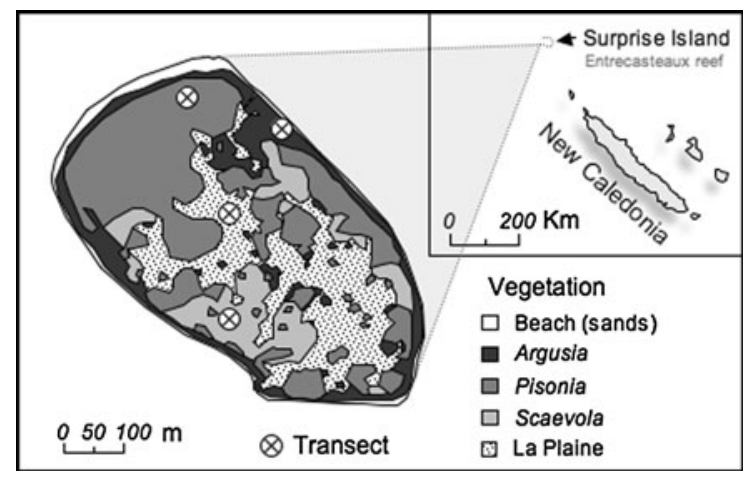

Fig. 1 Map of Surprise Island, Entrecasteaux Reefs, New Caledonia, showing the four distinct vegetation zones and the sampling plots equipment to this isolated oceanic island restricted survey length and methods that were employed for the assessment of fauna. An ant survey was conducted during 10 days in November 2004 in a plot in each vegetation type. To sample ant presence and abundance within each site, 24 pitfall traps were regularly placed in a square of $30930 \mathrm{~m}$ with $5 \mathrm{~m}$ spacing between traps. Pitfall traps were $6 \mathrm{~cm}$ diameter and $7 \mathrm{~cm}$-deep plastic vials partially filled with water and soap. They were placed on the ground during 24 h. Each habitat (one plot per habitat) was sampled on 1 day. The content of pitfall traps was preserved in $70 \%$ ethanol and analyzed in the laboratory to the species' level (identifications were confirmed by Hervé Jourdan, IRD, Nouméa, New Caledonia, and Jacques H. Delabie, CEPEC-CEPLAC, Itabuna, Brazil).

\section{Community parameters}

To describe the structure of each ant community, the components of species diversity $(\mathrm{H})$, species richness (S) and evenness (E) were estimated for each site from pitfall traps. The Shapon diversity index $(\mathrm{H})$ was estimated as: $\mathrm{H}=-\quad\left(\mathrm{p}_{\mathrm{i}} \log _{\mathrm{e}} \mathrm{p}_{\mathrm{i}}\right)$, where $\mathrm{p}_{\mathrm{i}}$ is the proportion of workers of the ith species in traps during the period of time considered. The Pielou evenness index $(\mathrm{J})$ was estimated as: $\mathrm{J}=\mathrm{H} / \mathrm{ln} \mathrm{S}$, where $\mathrm{S}$ is species richness and $\mathrm{H}$ is the Shannon diversity index. Evenness value ranges from 1 when all species are equally abundant to 0 when all individuals in the sample belong to the same species.

To estimate the true number of species in each habitat (total “expected” species), a sample-based randomization (re-sampling) procedure from EstimateS (Colwell 2006) was used: we computed species accumulation (rarefaction) curves, with the expected richness function Mao Tau and their 95\% CI curves (Colwell 2006). We computed sample-based rarefaction curves from empirical data of 23, 24, 22 or 21 pitfalls of LP, ARG, PIS or SCA, respectively (in LP, PIS and SCA some pitfall contents were emptied by rats or birds), sample order was randomized 50 times.

Foraging ecology of species: bait observations

Although ant species were readily distinguishable in the field, samples of all species were taken back to 
the laboratory and sent to taxonomists to confirm identification. Ant foraging activity was measured at baits during the course of 1 day in each habitat. Baits are an exceptionally rich food source useful to establish the daily rhythms of species (Cros et al. 1997). Eighteen pairs of baits were laid regularly over each study site. Baits were small plastic spoons with two different large food rewards (water-diluted honey and peanut butter). Each pair of baits (honey and peanut butter) was inside a box (transparent plastic container, $1991597.5 \mathrm{~cm}$ ) to prevent food consumption by rats, which had four lateral holes to allow ant access to food. The distance between spoons in the same box was $5-10 \mathrm{~cm}$ and the distance between boxes was 1-10 m (Electronic Supplementary Material, Fig. ESM_2). Baits were installed at 05:00 a.m., and the first bait observation was done at 06:00 a.m. (at least $30 \mathrm{~min}$ after bait installation). Each hour from sunshine to sunset (06:00 a.m. until 18:00 p.m.), the number of workers of each ant species feeding at each bait was recorded. Nocturnal activity at baits was not studied to prevent disturbance to the chicks or fledglings of seabirds that were in their nests (Surprise Island has an important seabird population and our study was done during the breeding season). The overall number of occupied baits was used as a measurement of the external activity of each species. Together with the hourly measurements of activity on baits, ground surface temperatures near the baits were measured every 15 min with HOBO's Data-Logger (two HOBO 4-channel external logger with four external temperature sensors were installed at each site). For each bait record we assigned a temperature value from the closest Data-Logger sensor and time. Distances between bait and temperature sensor were between 0.3 and $5 \mathrm{~m}$.

To quantify patterns of species activity rhythms similarity between each given pair of species, we used a proportional similarity index (PSI) or Czekanowski's index, based on Colwell and Futuyma (1971) proportional overlap. It was calculated between each species pair (species $\mathrm{i}$ and species $\mathrm{j}$ ) from hourly bait occupation (maximum bait occupation $=3$, time: 13 different hours): PSI $_{i j}=$ $1-0.5\left|p_{i k}-p_{h k}\right|$ where $p_{i k}$ is the number of baits occupied by species $\mathrm{i}$ at the time $\mathrm{k}$ and $\mathrm{p}_{\mathrm{hk}}$ is the bait occupation of the species $h$ at the same time $k$. The PSI overlap measure takes its minimum value of 0 when both species do not overlap at all, and its maximum value of 1 when activity rhythms of the two species are the same. To test whether foraging activity rhythms were influenced by competition within the habitats (i.e. whether species within the habitats were segregating their activity rhythms) a null model obtained from PSI values was applied for each habitat; a second null model was done for the whole island (with all habitats pooled). We calculated the observed PSI average of each habitat (or of the island) as the average of all PSI between the different species pairs found in the habitat (or in the island). Observed PSI average (PSI $\mathrm{OBS}_{\mathrm{OBS}}$ ) was compared to the average calculated from the randomized assemblages

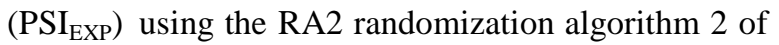
the EcoSim niche overlap model (Gotelli and Entsminger 2010). We used the same procedure described in Wittman et al. (2010) (1,000 iterations, niche breadth $=$ relaxed, zero states $=$ retained $)$, where details about randomization are given. In the absence of interspecific competitive interactions, time should be equally used by all species (RA2, resource state $=$ equiprobable). $\quad$ A significantly smaller observed PSI than randomized PSI implies interspecific competition and resource (activity time in this case) partitioning, whereas a significantly larger observed PSI might indicate shared resource utilization and a lack of competition (Gotelli and Entsminger 2010).

To quantify patterns of species composition similarity between each given pair of samples (bait vs. pitfall within sites, or between different pair of sites), the Chao's abundance-based Sørensen index (corrected for unseen species) (ChSI hereafter) was calculated by using the procedure from EstimateS (Colwell 2006). The standard deviation of Chao's estimator for ChSI was calculated from 200 randomized runs of data.

The position of each ant species in the dominance hierarchy was determined by analyzing interspecific interactions at baits, where species coexisting at the same periods of the day interacted actively. To determine the relative dominance of a species, the dominance index (DI) of each species was calculated as the ratio of encounters won (i.e., it drove away another species) and total interspecific encounters (Fellers 1987), there are many metrics for constructing dominance hierarchies (see de Vries et al. 2006; Bang et al. 2010; Dworschak and Blüthgen 2010), but 
this one is commonly used. To consider if the species won or lost, we analyzed which species was occupying the bait $1 \mathrm{~h}$ after the first encounter. All the Surprise Island species are mass-recruiters that may occupy the baits during a long time period, which excludes possible metrics biases due to different foraging strategies. The cases in which the bait was empty $1 \mathrm{~h}$ after the first encounter were not considered for calculations. If one or two species reappeared $2 \mathrm{~h}$ later (i.e. $1 \mathrm{~h}$ after the bait was ant free), it was considered as a new bait occupation event.

Estimation of maximal activity temperature and critical temperature

The maximal activity temperature (MAT) of each species is the temperature at which the foraging activity was greatest. It was estimated from field observations on baits, MAT being the temperature at which the species occupied the maximum number of baits across all habitats types. Bait data and temperature records were analyzed to estimate the effect of temperature on bait occupation for the most abundant species in each habitat. Statistical models were fitted with General Regression Models, GRM package from Statistica 8.0 (StatSoft 2007).

The critical thermal maximum (CTM) was measured at the laboratory by means of an electric Plactronic Selecta hot plate with a $5-200^{\circ} \mathrm{C}$ temperature range and $1^{\circ} \mathrm{C}$ accuracy. Following the Cerdá et al. (1998) protocol, only foragers of each species, i.e., workers collected outside the nest in the field, were used in these experiments. Each ant was placed on the surface of the hot plate in open containers with Fluon-painted inner walls, which prevented ants escaping. Each ant was exposed during $10 \mathrm{~min}$ to a given temperature and its behaviour was noted. After this test (thermal treatment), the individual was discarded to avoid heat accumulation and a different one was used. A total of twenty different individuals of each species were used for each temperature. For each temperature, the number of ants that began to have muscle spasms and died was noted. The temperature of the hot plate was progressively raised at intervals of $2^{\circ} \mathrm{C}$, from 20 to $50^{\circ} \mathrm{C}$ (depending on the thermal tolerance of each species) and new individuals were used each time. The CTM of each species was considered to be the temperature at which at least $50 \%$ of workers (10 individuals) died or lost muscular coordination after 10 min of exposure (Cerdá et al. 1998).

The difference between the CTM and MAT temperatures (CTM-MAT) was calculated for each species. This variable is an estimate of how close to (low values) or far from (high values) risk temperatures (i.e., CTM) is the maximum foraging temperature of the species (i.e., MAT).

Native and invasive ant species: testing the temperature effect on competition

The baits were checked every hour and the replacement of one species by another was noted. This information was used to evaluate how each ant species (native or introduced) interacted with the other species: in which situations each ant species succeeded in replacing any other ant species (success) and in which situations it was replaced by other ant species (failure). We also analyzed whether the success or failure of the native or introduced ants was regulated by temperature. A generalised linear model per species (data from all habitats pooled) was performed in which the success or failure was the dependent variable and a binomial distribution and a logit link function were used. Two independent variables were analyzed in separate analyses: temperature during the hour of the replacement and the number of degrees temperature increased or decreased during the hour when the replacement occurred. Generalised Linear Models were performed with the SAS package (GENMOD, v. 9.1.3., SAS Institute Inc. 2004).

Quantifying species co-occurrence: testing the competition hypothesis

The co-occurrence analysis tests whether the observed pattern differs from the pattern expected in the absence of the proposed mechanism, which in our case is interspecific competition. Separate matrices at each sampled site were created to analyze species co-occurrence. Matrices were based on two different sample lists of the species from each site collected: (1) in 24 pitfall trap samples along $24 \mathrm{~h}$; (2) in baits during $13 \mathrm{~h}$. EcoSim software was used to test for non-random patterns of species co-occurrence in the original presence/absence matrix. This original matrix was randomized to create 5,000 random 
matrices by reshuffling the elements of each row and column of the matrix, with the option of fixed sums for columns and rows (SIM9 simulation algorithm of EcoSim; Gotelli 2000; Gotelli and Entsminger 2001, 2010). A co-occurrence index, the Stone and Roberts' (1990) C-score, was calculated from the original matrix and compared to a frequency distribution produced by the C-scores indices of the random matrices. The C-score is an index negatively correlated to species co-occurrence, and therefore in a competitively structured community the C-score should be significantly higher than that expected by chance. If the C-score from the original matrix lies within the $95 \%$ frequency distribution of the randomized matrices, there is no evidence for deterministic processes influencing species distribution, whereas, if the index is beyond the 95\% confidence limits of randomized matrices, there should be biological mechanisms driving species co-occurrence (Ribas and Schoereder 2002). In the latter event, original species co-occurrence may be higher or lower than expected by random chance, and the biological explanations for such results are that there is less pairwise species co-occurrence (segregation) or more species co-occurrence (aggregation) than expected by chance, respectively (Sanders et al. 2003). Tail probabilities (two-tailed test) of the observed matrix were estimated by comparing it with the histogram of simulated values.

\section{Results}

Species composition and community parameters

A total of eight different species were identified from Surprise Island samples (Table 1). Among them, seven were introduced (or exotic) invasive species, and only one species, Pheidole oceanica, could be considered as a native species. Tetramorium simillimum was the most abundant species on the island, with $35.9 \%$ abundance (from pitfall catches), and the second most abundant was Pheidole oceanica, the native ant species, with $24.8 \%$ abundance at pitfall traps. The two sampling methods, pitfall traps and baits, gave a similar pattern of specific abundance (Table 1), but note that Cardiocondyla emeryi was only present in pitfall traps. There was a linear statistically significant relationship between pitfall catches and bait occupation (Pearson's $r=0.867$,

Table 1 Relative abundance of ant species in pitfall (\% P) and baits (\% B) at the four study sites

\begin{tabular}{|c|c|c|c|c|c|c|c|c|c|c|}
\hline \multirow{2}{*}{$\begin{array}{l}\text { Study site } \\
\text { Ant species }\end{array}$} & \multicolumn{2}{|c|}{ LA PLAINE } & \multicolumn{2}{|c|}{ ARGUSIA } & \multicolumn{2}{|c|}{ PISONIA } & \multicolumn{2}{|c|}{ SCAEVOLA } & \multicolumn{2}{|c|}{ ALL SITES } \\
\hline & $\% \mathrm{P}$ & $\% B$ & $\% \mathrm{P}$ & $\% \mathrm{~B}$ & $\% \mathrm{P}$ & $\% \mathrm{~B}$ & $\% \mathrm{P}$ & $\% \mathrm{~B}$ & $\% \mathrm{P}$ & $\% \mathrm{~B}$ \\
\hline Brachymyrmex obscurior & 2.5 & 25.0 & 0.9 & - & 22.2 & 11.2 & 4.6 & 5.4 & 3.0 & 8.9 \\
\hline Cardiocondyla emeryi & 1.2 & - & 1.4 & - & 1.9 & - & 4.0 & - & 2.1 & - \\
\hline Monomorium floricola & - & - & 13.4 & 15.6 & - & - & 7.2 & 18.3 & 5.9 & 10.5 \\
\hline Paratrechina longicornis & - & - & 77.8 & 79.2 & 13.0 & 11.2 & 1.0 & 3.3 & 22.2 & 25.8 \\
\hline Pheidole oceanica & 11.0 & 37.5 & 1.2 & - & - & 7.9 & 67.0 & 58.9 & 24.8 & 28.7 \\
\hline Tapinoma melanocephalum & 0.8 & - & 1.7 & 4.9 & 42.5 & 39.9 & 3.7 & 3.3 & 2.3 & 9.5 \\
\hline Tetramorium bicarinatum & - & - & - & - & 1.9 & - & 12.5 & 10.8 & 3.8 & 3.6 \\
\hline Tetramorium simillimum & 84.5 & 37.5 & 3.6 & 0.3 & 18.5 & 29.8 & - & - & 35.9 & 13.0 \\
\hline Total catches & \multicolumn{2}{|c|}{1,260} & \multicolumn{2}{|c|}{861} & \multicolumn{2}{|c|}{54} & \multicolumn{2}{|c|}{921} & & \\
\hline$\%$ empty baits & \multicolumn{2}{|c|}{56.2} & \multicolumn{2}{|c|}{40.6} & \multicolumn{2}{|c|}{63.1} & \multicolumn{2}{|c|}{31.1} & & \\
\hline S (observed species richness) & \multicolumn{2}{|c|}{5} & \multicolumn{2}{|c|}{7} & \multicolumn{2}{|c|}{7} & \multicolumn{2}{|c|}{7} & & \\
\hline Mao Tau (richness estimator) & \multicolumn{2}{|c|}{6} & \multicolumn{2}{|c|}{8} & \multicolumn{2}{|c|}{7} & \multicolumn{2}{|c|}{7} & & \\
\hline $\mathrm{H}$ & \multicolumn{2}{|c|}{0.575} & \multicolumn{2}{|c|}{0.816} & \multicolumn{2}{|c|}{1.499} & \multicolumn{2}{|c|}{1.153} & & \\
\hline $\mathrm{J}$ & \multicolumn{2}{|c|}{0.321} & \multicolumn{2}{|c|}{0.392} & \multicolumn{2}{|c|}{0.770} & \multicolumn{2}{|c|}{0.593} & & \\
\hline
\end{tabular}

Bold values are the most abundant species in each site and method. S represents the observed specific richness, Mao Tau is the expected richness (?95\% CI) from pitfall traps, H the Shannon's diversity index, J the Pielou's evenness index. Total catches values represent the total number of individuals caught in all pitfall traps of each site. The percentage of empty baits ( $\mathrm{n}=468$ baits per site), not taken into account when calculating the relative abundance in baits, is shown 
$\mathrm{P} \backslash 0.001)$. Not all species were present at all sites; we did not find all eight species in every habitat: the poorest habitat was LP, with only five species, while the other three habitats, PIS, SCA and ARG each had seven species. However, Mao Tau expected richness including the upper 95\% CI showed higher values than observed in all habitats (expected vs. observed species: LP, 6 vs. 5; ARG, 8 vs. 7; PIS, 7 vs. 6 species) except Scaevola (SCA, 7 vs. 7 species) (Table 1 and Electronic Supplementary Material, Fig. ESM_3). Shannon Diversity (H) and Pielou Evenness (J) indexes also showed great variability, PIS being the most diverse habitat, and LP the least diverse habitat (Table 1). Total catches at pitfall traps gave us an idea of ant abundances in each habitat: the lowest value was in PIS, with only 54 individuals collected (after $24 \mathrm{~h}$ ), while the highest was that of LP, with 1,260 individuals for the same trap period.

Daily activity patterns and foraging strategies

Foraging activity rhythms were measured to estimate the foraging overlap between species. Notwithstanding, daily activity patterns of all species studied were very similar (Fig. 2): a bimodal curve with two peaks, one after sunrise and another during the afternoon, and a stop or low activity level during the hottest central hours of the day. The only exception was Monomorium floricola in the SCA site, which had the maximum values of bait occupation between 10 and $15 \mathrm{~h}$, during the central hours of the day (Fig. 2d). Activity rhythm overlap between species pairs (PSI) ranged between 0.86 (high similarity) and 0.17 (low similarity), but $58 \%$ of values of the 31 species pairs considered had PSI values higher than 0.60 , showing a high degree of similarity between species activity rhythms. The observed PSI averages were larger than expected by chance (than the PSI generated from the null assemblages) in two sites, ARG and PIS (PSI ${ }_{\mathrm{OBS}}$ [ $\mathrm{PSI}_{\mathrm{EXP}}, \mathrm{P}=0.002$ and $\mathrm{P} \backslash 0.0001$, respectively), indicating that species shared the time of day in which they were active; and were not significantly different from randomness in the other two sites, LP and SCA (additional details are given in Electronic Supplementary Material, Tables ESM_4 and ESM_5). When rhythm overlap between species pairs was considered at the island level (all habitats pooled), observed PSI averages were larger than the PSI generated from the null assemblages $\left(\mathrm{PSI}_{\mathrm{OBS}} \boldsymbol{L P S I}_{\mathrm{EXP}}, \mathrm{P} \backslash 0.0001\right.$,
Electronic Supplementary Material, Table ESM_5), indicating that species were generally active at similar times of day, considering the island as a whole.

Activity patterns were linked to daily temperature values that varied according to vegetation (\% of canopy cover). Temperature showed great daily variability in the more open habitats (between 22 and $60^{\circ} \mathrm{C}$ in LP; and 22 and $59^{\circ} \mathrm{C}$ in $\mathrm{ARG}$ ), and less variability in the closed habitats (between 25 and $45^{\circ} \mathrm{C}$ in PIS; and 26 and $46^{\circ} \mathrm{C}$ in SCA) (Fig. 2). There was a significant linear negative relationship between bait occupation in each habitat and temperature (LP: $\mathrm{R}^{2}=0.904, \mathrm{P} \backslash 0.0001$; ARG: $\mathrm{R}^{2}=0.692, \mathrm{P}=0.0004$; PIS: $\mathrm{R}^{2}=0.388, \mathrm{P}=0.02$; SCA: $\left.\mathrm{R}^{2}=0.809, \mathrm{P} \backslash 0.0001\right)$. At higher temperatures, there were more empty baits at all sites.

Baits also provided information about species foraging strategies during food collection. Concerning bait occupation at the species-level, the highest value of the mean number of workers per bait (Table 2) was that of T. simillimum (45.8 workers per bait), followed by Ph. oceanica (40 workers per bait). When the percentage of baits occupied by more than 50 workers (as another measure of worker recruitment efficiency) was considered, T. simillimum had the highest value, with $28.9 \%$ of baits with more than 50 workers, while $\mathrm{Ph}$. oceanica was the second, with $27.1 \%$ of baits (Table 2). For both measures, both species were the most efficient bait users; the thirdranked bait-user was $P$. longicornis, with a mean value of 25 workers per bait and $7.7 \%$ of baits with more than 50 workers. Although the other species recruited fewer workers (mean values from 8 to 14 workers per bait), they were able to recruit 50 workers to the bait, but they did so only rarely (between 0.9 and $3.0 \%$ of baits). According to these values, all species were mass-recruiters.

\section{Temperature and bait exploitation}

Differences in bait exploitation could be due to different specific thermal requirements. Firstly, we analyzed the effect of temperature on bait occupation for the most abundant species in each habitat. At LP site, the relationship between ant presence on baits and temperature of the two most abundant species followed a very similar negative linear pattern (T. simillimum, $\mathrm{y}=86.88-1.80 \mathrm{x}, \mathrm{R}^{2}=0.887$, $\mathrm{P} \backslash 0.0001$; Ph. oceanica, $\mathrm{y}=92.38-1.94 \mathrm{x}, \mathrm{R}^{2}=$ 0.779, $\mathrm{P} \backslash 0.0001$ ) (Fig. 3a). At ARG site, the 
Fig. 2 Daily variation of temperature and relative presence of the different ant species on baits in each habitat: a La Plaine; b Argusia; c Pisonia; d Scaevola. Abbreviations: BO_Brachymyrmex obscurior; $\mathrm{MF}$ Monomorium floricola; PL-Paratrechina longicornis; PO_Pheidole oceanica; TB-

Tetramorium bicarinatum; TM-Tapinoma melanocephalum; TSTetramorium simillimum. Temperature values are mean $( \pm S E)$ of 8 sensors (except Scaevola: 3 sensors), recording ground temperatures every $15 \mathrm{~min}$ during $24 \mathrm{~h}$

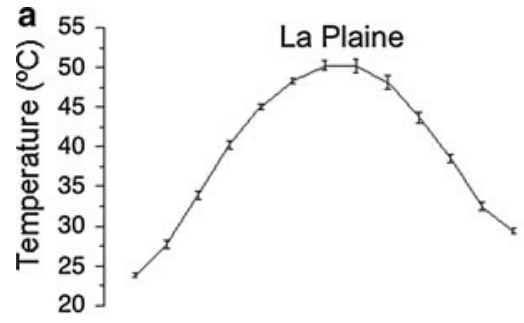

b
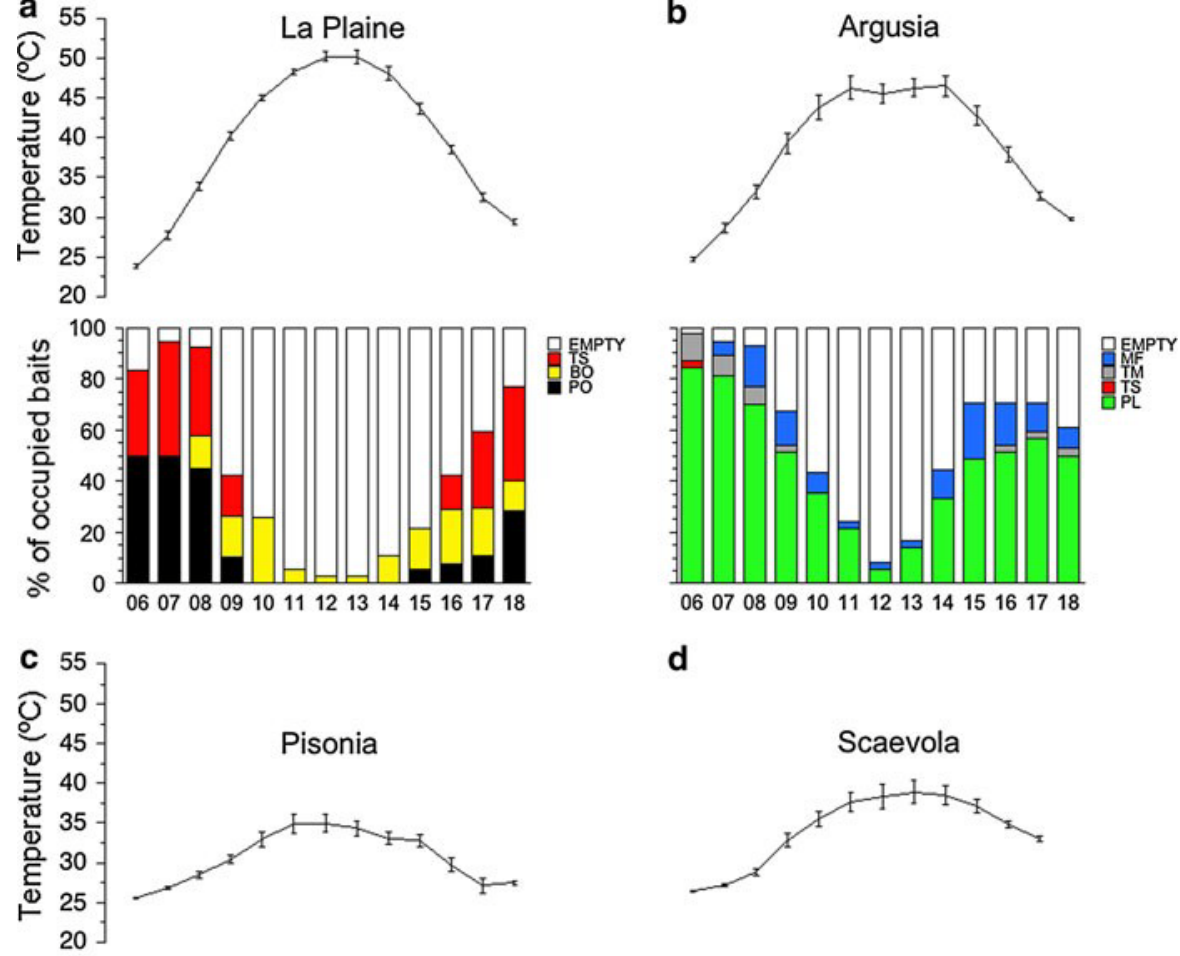

d

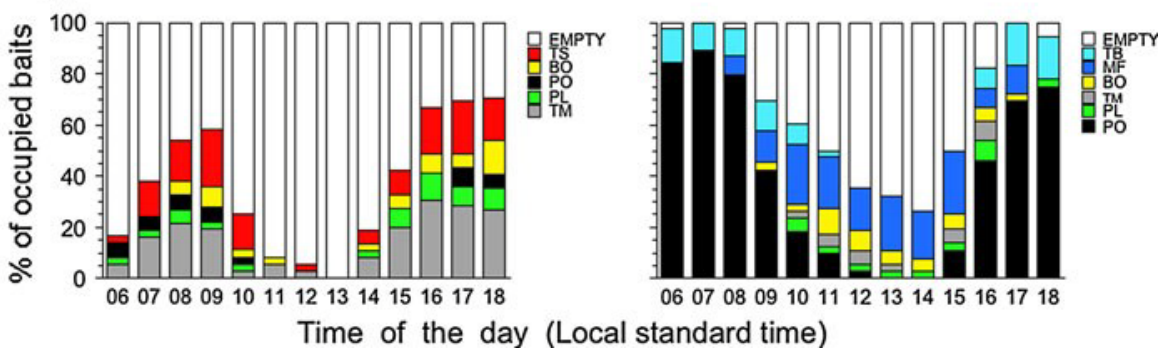

relationship was also negative and linear for P. longicornis $\left(y=151.9-2.78 x, \quad R^{2}=0.783\right.$, $\mathrm{P} \backslash 0.0001$ ) (Fig. 3b); but the relationship for M. floricola fitted a quadratic curve, with a slow increase of the number of occupied baits according to temperature, and a fall after $38^{\circ} \mathrm{C}(\mathrm{y}=-141.6$ ? $\left.8.57 x-0.117 x^{2}, R^{2}=0.604, P=0.0091\right)$ (Fig. 3b). At PIS site, the relationship of the two most abundant species fitted well a very similar quadratic curve for both species ( $\mathrm{T}$. melanocephalum, $\mathrm{y}=-676.6$ ? $47.7 \mathrm{x}-0.813 \mathrm{x}^{2}, \mathrm{R}^{2}=0.668, \mathrm{P}=0.004$; T. simillimum, $\mathrm{y}=-638.6-44.3 \mathrm{x}-0.747 \mathrm{x}^{2}, \mathrm{R}^{2}=0.778$, $\mathrm{P}=0.0002$ ) (Fig. 3c); at this site, the maximum temperature value was only $35^{\circ} \mathrm{C}$, but bait occupation by both ant species decreased when temperatures were higher than $30^{\circ} \mathrm{C}$. At SCA site, two of the most abundant species showed a negative linear relationship between bait occupation and temperature (T. bicarinatum, $\mathrm{y}=42.88-1.06 \mathrm{x}, \mathrm{R}^{2}=0.594, \mathrm{P}=0.002$; Ph. oceanica, $y=294.94-7.54 x, \quad R^{2}=0.928$, $\mathrm{P} \backslash 0.0001$ ), but a third species showed a positive linear relationship, increasing its bait exploitation when temperature increased $(\mathrm{M}$. floricola, $\mathrm{y}=$ -43.54 ? 1.68x, $R^{2}=0.742, \mathrm{P}=0.0002$ ) (Fig. 3d).

We analyzed MAT (temperature at which species performs the maximal foraging activity), and CTM (critical thermal temperature, which limits foraging activity of the species) of each species (Table 2). MAT ranged from $24^{\circ} \mathrm{C}$ (P. longicornis) to $37^{\circ} \mathrm{C}$ (M. floricola); and CTM was very similar among species, ranging from $38^{\circ} \mathrm{C}$ (Ph. oceanica minor workers) to $44^{\circ} \mathrm{C}$ (M. floricola, P. longicornis, B. obscurior). The native $\mathrm{Ph}$. oceanica had a low value of MAT $\left(26^{\circ} \mathrm{C}\right)$ and the lowest CTM values, but its activity rhythm 
Table 2 Ecological traits of the ant species from Surprise Island

\begin{tabular}{|c|c|c|c|c|c|c|c|c|}
\hline Ant species & $\begin{array}{l}\text { Geographical } \\
\text { native origin }\end{array}$ & $\begin{array}{l}\text { Worker } \\
\text { length (mm) }\end{array}$ & $\begin{array}{l}\mathrm{N} \text { workers } \\
\text { per bait } \\
(\text { mean } \pm \mathrm{SE})\end{array}$ & $\begin{array}{l}\% \text { of baits } \\
\text { with [50 } \\
\text { workers }\end{array}$ & $\begin{array}{l}\text { Dominance } \\
\text { index }\end{array}$ & $\begin{array}{l}\text { CTM } \\
(8 \mathrm{C})\end{array}$ & $\begin{array}{l}\text { MAT } \\
(8 \mathrm{C})\end{array}$ & $\begin{array}{l}\text { CTM- } \\
\text { MAT }\end{array}$ \\
\hline $\begin{array}{l}\text { Brachymyrmex } \\
\text { obscurior }\end{array}$ & Neotropics ${ }^{\mathrm{a}}$ & $1.5-2.0$ & $8.6 \pm 1.4$ & 1.1 & 0.480 & 44 & 26 & 18 \\
\hline $\begin{array}{l}\text { Cardiocondyla } \\
\text { emeryi }\end{array}$ & West Africa ${ }^{\mathrm{b}}$ & $1.8-2.1$ & - & - & - & - & - & - \\
\hline $\begin{array}{l}\text { Monomorium } \\
\text { floricola }\end{array}$ & Tropical Asia ${ }^{\mathrm{c}}$ & $1.5-2.0$ & $12.7 \pm 1.3$ & 0.9 & 0.517 & 44 & 37 & 7 \\
\hline $\begin{array}{c}\text { Paratrechina } \\
\text { longicornis }\end{array}$ & SE Asia ${ }^{d}$ & $2.3-3.0$ & $25.5 \pm 1.5$ & 7.7 & 0.476 & 44 & 24 & 20 \\
\hline \multirow[t]{2}{*}{ Pheidole oceanica } & South Pacific ${ }^{\mathrm{e}}$ & Major 3.5-4.2 mm & $40.0 \pm 2.0$ & 27.1 & 0.686 & 40 & 26 & 14 \\
\hline & & Minor 2.1-3.0 mm & & & & 38 & & 12 \\
\hline $\begin{array}{l}\text { Tapinoma } \\
\text { melanocephalum }\end{array}$ & Unknwon $^{\text {b,e }}$ & $1.3-1.9$ & $14.2 \pm 2.1$ & 3.4 & 0.235 & 42 & 30 & 12 \\
\hline $\begin{array}{l}\text { Tetramorium } \\
\text { bicarinatum }\end{array}$ & SE $\operatorname{Asia}^{\mathrm{f}}$ & $3.4-4.5$ & $10.4 \pm 1.4$ & 2.3 & 0.500 & ? & 32 & - \\
\hline $\begin{array}{r}\text { Tetramorium } \\
\text { simillimum }\end{array}$ & Tropical Africa & $2.0-2.7$ & $45.8 \pm 5.6$ & 28.9 & 0.333 & 42 & 28 & 14 \\
\hline
\end{tabular}

Dominance index of each species is calculated as the ratio of won cases and total (won ? lost) cases for observed replacements on baits in all habitats

CTM critical thermal maximum, MAT maximal activity temperature

a McGlynn (1999); ${ }^{\text {b }}$ Seifert (2003); ${ }^{\mathrm{c}}$ Wetterer (2010); ${ }^{\mathrm{d}}$ Wetterer (2008); ${ }^{\mathrm{e}}$ Wilson and Taylor (1967a, b); ${ }^{\mathrm{f}}$ Bolton (1979)

greatly overlapped with the introduced species (see Fig. 2a, d).

Temperature and interference on baits: hierarchy of dominance

From the outcome of bait interactions between pairs of species (a total of 71 observed interspecific interactions) we calculated the Dominance index (DI) of each species, which ranged from 0.23 (T. melanocephalum) to 0.69 (Ph. oceanica) (Table 2). The hierarchy of species from top to bottom according to DI was: Ph. oceanica $\mathbf{E}$ M. floricola โ T. bicarinatum โB. obscurior $\mathbf{E}$ P. longicornis โ T. simillimum โ T. melanocephalum. The only native ant species, Ph. oceanica, was the top competitor in the dominance hierarchy. It was frequently observed (23 cases from a total of 71 observed interspecific interactions) attacking and displacing other species from baits.

Generalised linear model of the success of the native ant in replacing invasive ants on baits showed that decreasing temperatures significantly benefited the success of the native ant $\mathrm{Ph}$. oceanica, while the temperature itself did not significantly affect its success (Table 3). Ph. oceanica successfully replaced invading ants when the temperature decreased and was replaced on a bait when the temperature increased (Fig. 4a). Indeed, the native ant succeeded in replacing the invading ant species in the evening (between 15.00 and $18.00 \mathrm{~h}$. LST), while it was replaced by invasive ants in the late morning (between 7.00 and $10.00 \mathrm{~h} \mathrm{LSD).}$

On the other hand, the success of the non-native ants in replacing Surprise Island's other species (native or otherwise) on baits was not affected by temperature, except in the case of $\mathrm{M}$. floricola, whose success was significantly but negatively affected by temperature (Table 3; Fig. 4b). It succeeded in replacing the other ant species in the early morning (between 6.00 and $9.00 \mathrm{~h} \mathrm{LST}$ ) when temperatures were lower, while it was replaced by other ants in the afternoon (between 14.00 and $17.00 \mathrm{~h} \mathrm{LST).}$ M. floricola was significantly more successful in replacing its competitors when the temperature 
Fig. 3 Effect of temperature on bait occupation by the most abundant species in each site: a La Plaine, b Argusia; c Pisonia; d Scaevola. All fitted relationships are statistically significant (see "Results" section for fitted equations and statistical details). Most abundant species abbreviations: TSTetramorium simillimum, PO-Pheidole oceanica, PL-Paratrechina longicornis, MFMonomorium floricola, TM-Tapinoma melanocephalum, TBTetramorium bicarinatum

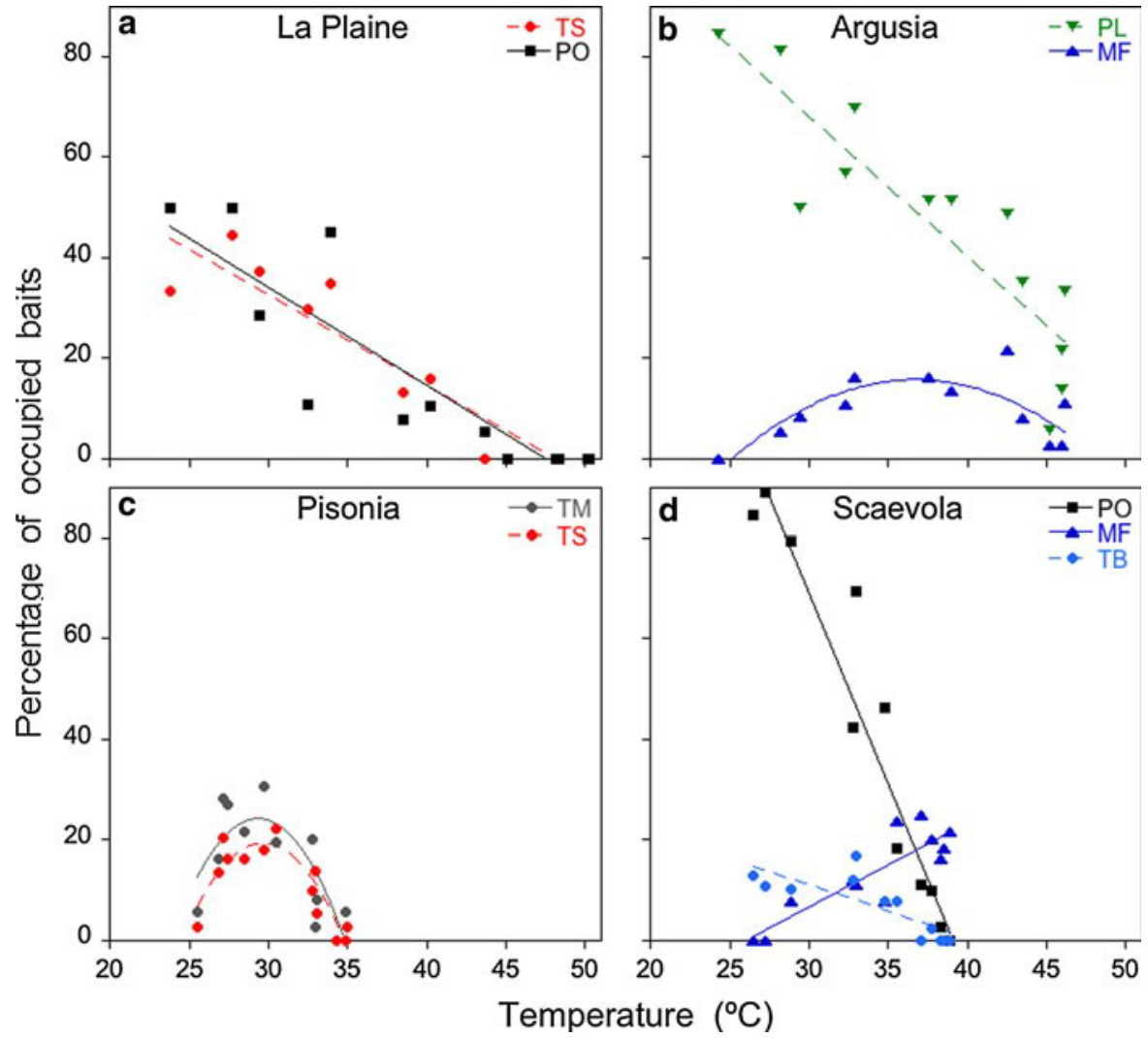

Table 3 Effects of temperature and of the increment of temperature on the success of each ant species in replacing other ant competitors at baits

\begin{tabular}{|c|c|c|c|c|c|c|c|c|}
\hline \multirow{2}{*}{$\begin{array}{l}\text { Effect } \\
\text { Ant species }\end{array}$} & \multicolumn{4}{|c|}{ Temperature } & \multicolumn{3}{|c|}{ Temperature increment } & \multirow[b]{2}{*}{ Sign } \\
\hline & $\mathrm{df}$ & $P^{2}$ & $\mathrm{P}$ & Sign & $\mathrm{df}$ & $1^{2}$ & $\mathrm{P}$ & \\
\hline Brachymyrmex obscurior & 27 & 0.40 & 0.530 & & 27 & 12.95 & 0.0003 & ? \\
\hline Monomorium floricola & 28 & 4.80 & 0.028 & - & 28 & 10.39 & 0.001 & $?$ \\
\hline Paratrechina longicornis & 17 & 1.47 & 0.226 & & 17 & 0.29 & 0.593 & \\
\hline Pheidole oceanica & 29 & 3.31 & 0.068 & & 29 & 41.05 & $<0.0001$ & - \\
\hline Tapinoma melanocephalum & 13 & 0.11 & 0.743 & & 13 & 2.00 & 0.157 & \\
\hline Tetramorium bicarinatum & 5 & 2.47 & 0.116 & & 5 & 1.36 & 0.243 & \\
\hline Tetramorium simillimum & 12 & 1.02 & 0.312 & & 12 & 7.60 & 0.006 & - \\
\hline
\end{tabular}

df, $\left.\right|^{2}$, and P are statistics for the Generalized Linear Models performed; in bold when the analysis was significant. The sign of the relationship is shown only for statistically significant models: ? means that replacement success increases when temperature is higher or when temperature is increasing; - means that success is negatively related with temperature, or that success increases when temperature is decreasing

increased (Fig. 4b), and a similarly significant effect was observed for Brachymyrmex obscurior; but Tetramorium simillimum was significantly more successful in bait replacement when the temperature decreased (Table 3).
Species co-occurrence: testing null models

When we analyzed the set of species from catches in 24 h-pitfall traps at each of the four sites studied, species co-occurred randomly with respect to one 


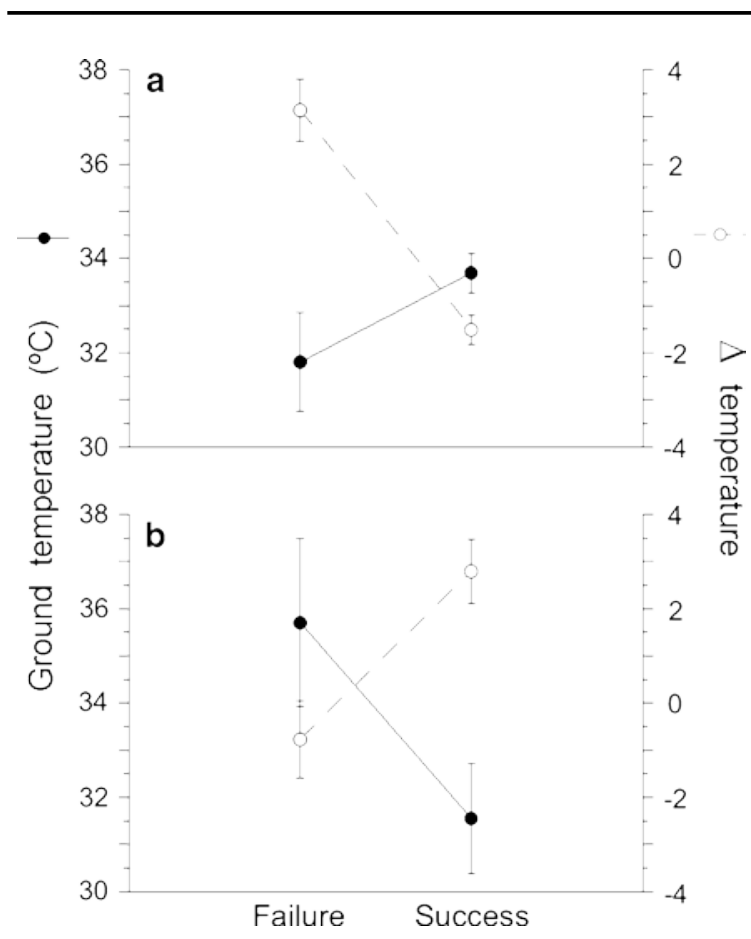

Fig. 4 Effects of temperature on the success of a Pheidole oceanica in replacing exotic ant species at baits; and b Monomorium floricola in replacing other ant species. Left Y-axis (black dots): ground temperature (in ${ }^{\circ} \mathrm{C}$ ), right $\mathrm{Y}$-axis (white dots): difference of temperature before and after the species replacement at bait

another in any of the habitats (Fig. 5a): no significant pattern of co-occurrence between the species of Surprise Island was observed in each different habitat. When we ran the analysis using only the species that were recorded on baits during the day, we obtained different results (Fig. 5b). At two of the sites (LP and SCA), species co-occurrence less frequently (higher C-score) than expected by chance; that is ant species were segregated with respect to one another. At the other two sites (ARG and PIS), species cooccurred randomly with respect to one another (additional details are given in Electronic Supplementary Material Table ESM_6).

\section{Discussion}

Ant communities on the small Surprise Island were composed of seven introduced species and only one native species that dominated the habitats where it was present. The native ant Pheidole oceanica can be considered native of the Pacific region (Wilson and

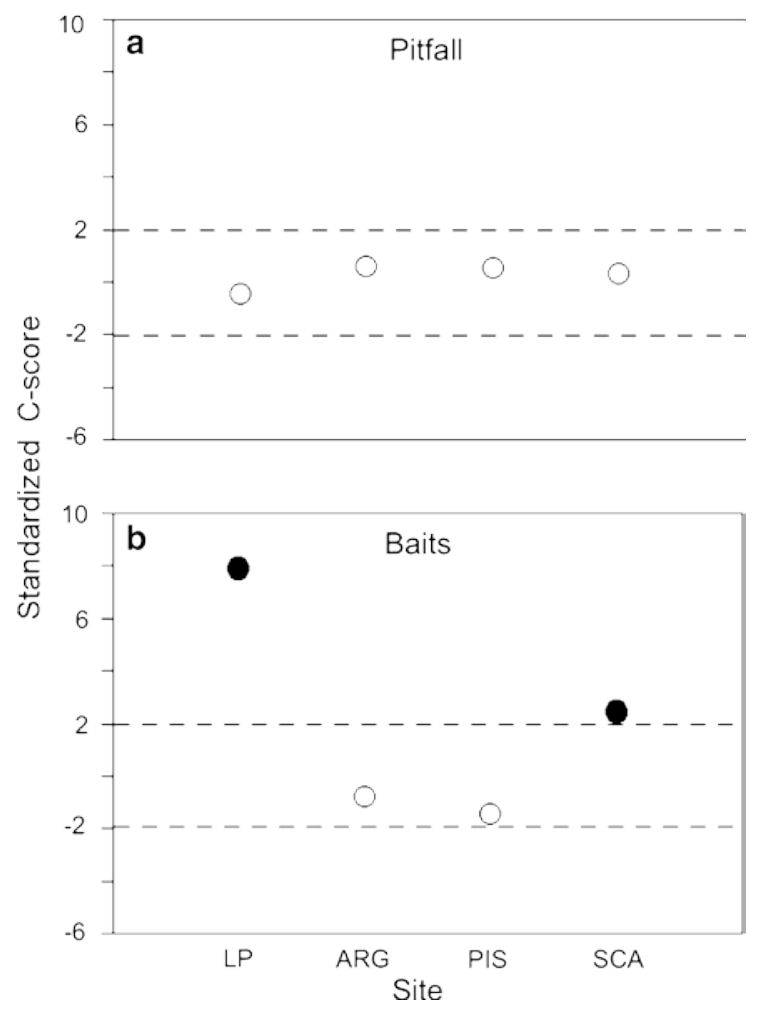

Fig. 5 Standardized C-score values at each study site (LP La Plaine, ARG Argusia, PIS Pisonia, SCA Scaevola) from a pitfall catches and $b$ bait observations. The dotted lines represent 1.96 standard deviations, the approximate level of statistical significance $(\mathrm{P} \backslash 0.05)$. Thus, the larger standardized C-scores (filled circle) the less co-occurrence compared with a randomly assembled community, while values within the dotted lines (open circle) correspond to a random pattern of organization

Taylor 1967b; Wetterer 2002). The introduced species are from very different corners of the world (neotropics, Africa, and Asia; see details and references in Table 2), but are very successful tramp species (Wilson and Taylor 1967b; McGlynn 1999). On Surprise Island local assemblages seem not to respond to competitive processes: species-specific activity rhythms mostly overlapped and were similarly temperature limited. However, temperature affected the competitive success of the dominant species Ph. oceanica.

Ant species richness and diversity had very low values in all four habitats, as is common for oceanic islands (Wilson and Taylor 1967a; Morrison 1996a; Herben 2005; Ingram et al. 2006). Ant species composition was not very original: most of the species (six exotic and the native species) are present 
on other Pacific islands, such as Samoa (Wilson and Hunt 1967), Tonga (Wetterer 2002), Fiji (Ward and Wetterer 2006) and some of the Society islands (Morrison 1996a). Each habitat on Surprise Island had a different ant composition with a different most abundant species: Tetramorium simillimum in LP, Paratrechina longicornis in ARG, Tapinoma melanocephalum in PIS, and Ph. oceanica in SCA. The native $\mathrm{Ph}$. oceanica is among the ecologically dominant species on many Pacific oceanic islands (Morrison 1996a, b). Background information about the biology and ecology of these introduced species in their native communities is non-existent. In its introduced range, $\mathrm{T}$. simillimum can achieve dense populations in open and disturbed habitats, but on Floreana Island in the Galápagos it is more abundant in natural non-human-impacted habitats (von Aesch and Cherix 2005); T. bicarinatum is mostly arboreal (on Surprise Island it nested inside the Scaevola or Pisonia branches), while workers forage both arboreally and on the ground (Wilson and Taylor 1967a); $\mathrm{T}$. bicarinatum is found in mangrove habitats around the world, M. floricola has large colonies nesting in trees and bushes (McGlynn 1999; Wilson and Taylor 1967a); B. obscurior is well suited to extreme, marginal environments such as small Bahamian cays, probably because it is not a strong competitor (Morrison 2006); T. melanocephalum is an urban pest, but it has never been described as replacing native species in natural environments (von Aesch and Cherix 2005); P. longicornis is an opportunist tramp species that may become ecologically dominant in some introduced habitats (Wetterer 2008; O’Dowd et al. 2003). All these exotic species are opportunists: they are the first to find the baits, but they abandon the food resources when workers of more dominant species arrive (McGlynn 1999; von Aesch and Cherix 2005; Wetterer 2008). This is not the case of Ph. oceanica on Surprise and other Pacific islands, where it always acts as a dominant species which recruits large numbers of workers and aggressively excludes other species from baits (Morrison 1996b).

Temperature and activity rhythms

The influence of environmental conditions on activity rhythms may determine the diversity and structure of ant communities in different habitats (Cros et al. 1997).
Ant communities typically display complex temporal dynamics, with co-occurring species often having markedly different foraging times (Andersen 2008 and references therein). The adoption of alternative activity rhythms by different sympatric species might reduce the intensity of their interaction and permit more effective partitioning of available resources (Baroni Urbani and Aktaç 1981; Cros et al. 1997). Thermal conditions are of special importance because the activity of small ectothermic ants will be restricted to those periods when surface conditions permit physiologically tolerable body temperatures (Marsh 1985; Cros et al. 1997; Cerdá et al. 1998). Abiotic effects on communities with few native and one invader species have been relatively well studied (e.g. Holway et al. 2002a; Menke and Holway 2006; Thomas and Holway 2005). However, previous information about these effects on communities composed of different invaders is very scarce (but see Wetterer et al. 2006).

On Surprise Island, daily temperature fluctuations were relatively similar in the four habitats, but in the two more open habitats (LP and ARG) temperatures showed a greater daily variation, with maximum values of ground surface temperature close to $60^{\circ} \mathrm{C}$, while in the closer habitats (SCA and PIS) they "only" reached $46^{\circ} \mathrm{C}$. Thus, areas with greater vertical stratification of vegetation, such as "forest" (PIS) or closed shrub (SCA), were better protected against sun exposure than more open habitats, and had less fluctuating temperatures over a greater proportion of their ground surface. Adoption of alternative activity rhythms by sympatric species may reduce interactions and permit more effective partitioning of available resources (Baroni Urbani and Aktaç 1981; Cros et al. 1997). Temporal separation is especially pronounced in hot environments, which often support highly thermophilic and risk-prone species capable of tolerating high temperatures that are lethal to other ant species, giving them exclusive access to resources during these times (Cerdá et al. 1998; Andersen 2008). On Surprise Island, however, local processes were different: at the hottest hours there were no foragers of any species. All species were potentially dominant and had similar thermal requirements (see CTM and MAT). Most of the Surprise species were risk-averse in the Cerdá et al. (1998) sense: they were heat-intolerant species that foraged well far from their critical thermal limits; 
their MAT values were between 24 and $30^{\circ} \mathrm{C}$ (ground surface temperatures), and differences CTM-MAT varied between 12 and $20^{\circ} \mathrm{C}$. The only exception was Monomorium floricola, which had a higher MAT value $\left(37^{\circ} \mathrm{C}\right)$ and a lower CTM-MAT difference (only $7^{\circ} \mathrm{C}$ ). However, its relative thermophyly was not sufficient to consider a temporal partitioning of food exploitation: 65\% of values of activity rhythm overlap between species pairs (PSI) were higher than 0.60 , showing a high degree of similarity between Surprise species activity rhythms.

Temperature and competition: effects on dominance

Ant species have been grouped into competitive hierarchies based mainly on behavioural differences in communication and aggressiveness (Savolainen and Vepsäläinen 1988; Savolainen et al. 1989; Cerdá et al. 1997; Bestelmeyer 2000): behaviourally dominant species are highly aggressive and subordinates are less aggressive. Each ant community from Surprise Island had a different dominant species, but the same species that was dominant in one habitat (because it won on interspecific interactions at baits) was dominated (it lost at bait interactions) in another habitat (we use the term dominated because it is only locally or temporally subordinate). Many studies focus their attention on the role of dominant species in communities (Savolainen and Vepsäläinen 1988; Gibb and Hochuli 2004; Parr 2008). However, any species that is abundant and tends to win competitive interactions with other species could be considered locally dominant. In all Surprise Island habitats, the species most represented at baits was the most abundant (abundance in pitfall catches). It could be considered a mosaic-like pattern, but the mosaic concept, according to Room (1971) is defined as the distribution of dominant ant species in patches, with mutually exclusive territories that do not overlap. This was not the case for the Surprise communities, because there was no mutual exclusion between locally dominant species.

The relationship between bait occupation and temperature on Surprise Island was chiefly linearly negative, although quadratic for some species. When temperature was higher than $35^{\circ} \mathrm{C}$, most baits (ca. $80 \%$ ) were empty. The only exception was Paratrechina longicornis at ARG site, which at a ground surface temperature of $45^{\circ} \mathrm{C}$ was present on $33 \%$ of baits, although it occupied baits in the shade or very close to vegetation. Another case of relative thermophyly was Monomorium floricola at SCA site: its presence on baits increased linearly with temperature, but it achieved no more than 22\% occupation when temperature reached $38^{\circ} \mathrm{C}$. From SCA bait observations, it seemed that $\mathrm{M}$. floricola had a preference for foraging in the morning and at midday. Other authors have observed the same diurnal pattern of activity in this species in the Galapagos islands (Meier 1994; von Aesch and Cherix 2005) suggesting that it allows the species to prevent or diminish interspecific competition.

In Mediterranean communities, where environmental factors show important daily variations (similar to the observed daily pattern on Surprise Island), the limited thermal tolerance of behaviourally dominant species compared with that of subordinates disrupts the expected transitive hierarchies. This thermal tolerance allows a far greater dominance in the ecosystem by subordinate species than might be expected from their relative abundance and fighting abilities (Cerdá et al. 1997). In Surprise Island communities, where there were no marked differences to classify the species as dominant or subordinate (except $\mathrm{Ph}$. oceanica, all are opportunists and may behave as dominant or not), it is more difficult to disentangle the effect on different species. In a New Zealand ant community, Stringer et al. (2007) observed that the native Pheidole rugosula occupied more baits when temperatures were between 20 and $30^{\circ} \mathrm{C}$, and the invasive Monomorium sydneyense when temperatures were between 30 and $40^{\circ} \mathrm{C}$; it appears that $\mathrm{Ph}$. rugosula dominates in all but the highest temperature ranges. When we analyzed the effect of temperature on the outcome of interspecific interactions for the two highest dominance-ranked species we observed the following pattern: the top dominant and native $\mathrm{Ph}$. oceanica was more successful when the temperature decreased (afternoon and evening) and mean temperature value was ca. $33^{\circ} \mathrm{C}$; the second dominant, the invasive $\mathrm{M}$. floricola, was more successful when the temperature increased (morning and midday) and mean temperature value was ca. $31^{\circ} \mathrm{C}$. On Floreana Island (Galapagos), M. floricola had a lower dominance score, and von Aesch and Cherix (2005) suggested that it is not a good competitor in direct interspecific interactions. 
On Surprise Island it ranked second in dominance from bait interactions, but we had no observations at night. This species produces a venomous substance (2.5-dialkylpyrrolidines) in its poison gland which it uses to repel other ant species in competitive interactions at food resources (Jones et al. 1982). Our observations agree with those of Sarty et al. (2006) in Tokelau atoll, where M. floricola have fighting abilities superior to Anoplolepis gracilipes (which sprays formic acid) and displaced other ant species from baits. This may be a similar case to Monomorium minimum in North America, which persists on baits both through its use of chemical defensive compounds and its tolerance of warm temperatures (Adams and Traniello 1981). According to Wetterer (2010), although there is little information on the importance of $\mathrm{M}$. floricola in natural environments, it is probably often overlooked and its abundance and ecological importance is underestimated.

Ant community composition in each Surprise Island habitat seems not to respond to competition or other deterministic processes. Ribas and Schoereder (2002) suggested that in ant species distributed in mosaics, species distribution may arise due to stochastic processes-biotic or abiotic processesthat have not been taken into account. Von Aesch (2006) attributed the lack of competition-derived structure in Floreana Island ant communities to the dynamics of the system (temporal changes in species abundance and composition). While it is an important factor in community organization on other Pacific islands (Morrison 1996a, b), interspecific competition does not seem to be intense enough to influence the actual distribution of species within or among islands. This holds with the important exception of Pheidole fervens-Ph. oceanica-Solenopsis geminata interaction (Morrison 1996a, b). Even if the distribution of different species in each habitat of Surprise Island seems to be random, we detected some degree of structure/co-occurrence in the ant community of two habitats (LP and SCA) when foraging at baits. Differences between results from pitfall trap and bait C-scores could be explained by the fact that pitfall traps measured the presence of each species in each habitat along a day (that is, during $24 \mathrm{~h}$ ), while baits measured the presence of each species in a bait at a specific moment of the day. Thus, although from pitfall data we obtained a random co-occurrence of the presence of species in each habitat, segregation occurred when foraging in LP and SCA habitats. Nevertheless, segregation is not temporal but spatial because foraging activity overlap in both habitats and is not significantly different from randomness. Both habitats had the highest abundance of $\mathrm{Ph}$. oceanica and segregation could be the effect of its presence.

Native ant species holding out against invaders?

Probably the most salient result of our study is the "resistance" ability of the native species currently confronted by the exotic tramp species on Surprise Island. In some New Caledonian ant communities, Le Breton et al. (2007) observed an "inappropriate" or non-adaptive response of native dominant Pheidole species (no Ph. oceanica) to the invading little fire ant Wassmannia auropunctata, and, thus, the importance of enemy recognition in the organization of ant communities. In this study, we have shown that $\mathrm{Ph}$. oceanica has an adequate response to several exotic species. The traditional view of biotic resistance against invaders has been either black or white, success or failure (Carlsson et al. 2010); in the case of invasive ants, they are mostly successful (especially on oceanic islands or in disturbed habitats), but studies showing cases of native ant biotic resistance against invaders are increasing (Rao and Vinson 2004; Wetterer et al. 2006; Blight et al. 2010; Masciocchi et al. 2010).

As Feener et al. (2008) stated, invasive species increase the global biota homogenization, which may increase as interactions between invasive and native species lead to local extirpation of native species. Alternatively, it may occur in the absence of such interactions simply because invasive species have broader environmental tolerances and can thus spread more widely than native species (Feener et al. 2008). For example, climatic niche partitioning allows coexistence between some invasive fruit flies on La Réunion Island, but the only endemic species lacks a private climatic niche and it has become a very rare species (Duyck et al. 2006). We do not know the previous history of ant communities on Surprise Island, but the snapshot that we have obtained from our data shows that the 'indomitable' native species Pheidole oceanica is currently holding out against the invaders. Two important life history traits of $\mathrm{Ph}$. oceanica may provide it with an advantage to resist 
invasion: its very efficient mass recruitment system (with a mean of 40 workers recruited for a bait, to collect food or to defend the food resource) and the existence of a big-headed soldier caste (it is the only species with "soldiers" or major workers on the island), specialized in defending food resources and, when necessary, attacking the workers of other species. Invasion on islands could be seen as a lottery: depending on the invaders and the native ants' life traits, invasion could have a low or a high success rate. In ants, the outcome of interference competition at the colony level depends on asymmetries in recruitment response or local density (often reflective on colony size) (Holway et al. 2002b); but on Surprise Island these asymmetries are not met: $\mathrm{Ph}$. oceanica is one of the most efficient species recruiting for food sources, and its colony size is similar to the non-native species. The two most harmful tramp species in New Caledonia, Wasmannia auropunctata and Pheidole megacephala (Le Breton 2003; Le Breton et al. 2005) or Anoplolepis longipes on other Pacific islands (O’Dowd et al. 2003; Sarty et al. 2006; Ward and Beggs, 2007), are absent from Surprise Island. These species are "extirpators" or superdominants, monopolizing food resources and controlling territory. Their absence allowed communities of Surprise Island to have a hierarchy of dominance between invasive ants and a natural habitat where the top dominant is the only native species. This study constitutes a first approach, the absence of historical records making it difficult to discuss the processes in a more general framework. Since 2003, a long-term research project about Surprise Island ant communities has been underway which will, we hope, fill the current gap. More in-depth studies to elucidate the mechanisms of ecological dominance of Ph. oceanica and comparison with ant communities of other similar islands (with the same or other native species) could provide information conducive to a better understanding of invasibility, one of the most important threats to biodiversity.

Acknowledgments We would like to thank the French Navy in New Caledonia, especially the commander and crew of "La Moqueuse", for transport onto the island; Isabelle Brun for logistic assistance at the "Grande Terre"; Francisco Carro (Paco), Jean-Louis Chapuis, Vincent Hulin and Mathias Gerhardt helped in the daily routine on the island; and Paco also in the ant field work. We are very grateful to Hervé Jourdan (IRD, Nouméa) and Jacques H. Delabie (CEPEC-CEPLAC,
Itabuna) for ant identification. Funds were provided by the French Agence Nationale de la Recherche to FC. Thanks are due for very helpful comments to Nate Sanders, to two anonymous referees, to Stephen Gregory and Donna Harris during ESE coffee meetings, and to EBD Ant Group members (Raphaël Boulay, Ana Carvajal, Michael Jowers, Jessica Pearce-Duvet, Camille Ruel and Louise van Oudenhove) during lab meeting. Thanks to Nick Gotelli for help with EcoSim; to Neus MariMena for pitfall trap analysis of the first survey in 2003; and to Javi Retana and Dan Simberloff for accurate and constructive comments on a previous draft and during Caut's Ph.D. thesis dissertation, respectively. Jacqueline Minett Wilkinson and Michael J. Jowers revised the English. A first version was drafted during a XC sabbatical stay in France supported by the Spanish Ministry of Education and Science (Sabbatical PR2004-0539, PR2006-0412). All experiments comply with current Spanish and French laws.

\section{References}

Adams ES, Traniello JFA (1981) Chemical interference competition by Monomorium minimum (Hymenoptera: Formicidae). Oecologia 51:265-270. doi:10.1007/BF00540612

Andersen AN (1992) Regulation of "momentary" diversity by dominant species in exceptionally rich ant communities of the Australian seasonal tropics. Am Nat 140:401-420. doi:10.1086/285419

Andersen AN (2008) Not enough niches: non-equilibrial processes promoting species coexistence in diverse ant communities. Austral Ecol 33:211-220. doi:10.1111/j. 1442-9993.2007.01810.x

Bang A, Deshpande S, Sumana A, Gadagkar R (2010) Choosing and appropriate index to construct dominance hierarchies in animal societies: a comparison of three indices. Anim Behav 79:631-636. doi:10.1016/j.anbehav.2009.12.009

Baroni Urbani C, Aktaç N (1981) The competition for food and circadian succession in the ant fauna of a representative Anatolian semi-steppic environment. Mitt Schweiz Entomol Gess 54:33-56

Bestelmeyer BT (2000) The trade-off between thermal tolerance and behavioural dominance in a subtropical South American ant community. J Anim Ecol 69:998-1009. doi: 10.1111/j.1365-2656.2000.00455.x

Blight O, Provost E, Renucci M, Tirard A, Orgeas J (2010) A native ant armed to limit the spread of the Argentine ant. Biol Invasions 12:3785-3793. doi:10.1007/s10530-010-9770-3

Bolton B (1979) The ant tribe Tetramoriini (Hymenoptera: Formicidae). The genus Tetramorium Mayr in the Malagasy region and in the New World. Bull Br Mus nat Hist (Ent) 38:129-181

Brandao CRF, Paiva RVS (1994) The Galapagos ant fauna and the attributes of colonizing ant species. In: Williams DF (ed) Exotic ants: biology, impact, and control of introduced species. Westview Press, Boulder, pp 1-10

Carlsson NOL, Jeschke JM, Holmqvist N, Kindberg J (2010) Long-term data on invaders: when the fox is away, the mink will play. Biol Invasions 12:633-641. doi: 10.1007/s10530-009-9470-z 
Caut S, Angulo E, Courchamp F (2009) Avoiding surprise effects on Surprise Island: control in a multitrophic level perspective. Biol Invasions 11:1689-1703. doi:10.1007/ s10530-008-9397-9

Cerdá X, Retana J, Cros S (1997) Thermal disruption of transitive hierarchies in Mediterranean ant communities. J Anim Ecol 66:363-374

Cerdá X, Retana J, Cros S (1998) Critical thermal limits in Mediterranean ant species: trade-off betwen mortality risk and foraging performance. Funct Ecol 12:45-55. doi: 10.1046/j.1365-2435.1998.00160.x

Chesson P, Huntly N (1997) The roles of harsh and fluctuating conditions in the dynamics of ecological communities. Am Nat 150:519-553. doi:10.1086/286080

Colwell RK (2006) EstimateS: statistical estimation of species richness and shared species from samples. Version 8.0. User's guide and application: http://viceroy.eeb.uconn. edu/EstimateS. Accessed 04 June 2007

Colwell RK, Futuyma DJ (1971) On the measurements of niche breadth and overlap. Ecology 52:567-576. doi: $10.2307 / 1934144$

Cros S, Cerdá X, Retana J (1997) Spatial and temporal variations in the activity patterns of Mediterranean ant communities. Ecoscience 4:269-278

CTRDP (1987) Ecologie en Nouvelle Calédonie. Centre Territorial de Recherche et de Documentation, Nouméa, New Caledonia

de Vries H, Stevens JMG, Vervaecke H (2006) Measuring and testing the steepness of dominance hierarchies. Anim Behav 71:585-592. doi:10.1016/j.anbehav.2005.05.015

Duyck PF, David P, Quilici S (2006) Climatic niche partitioning following successive invasions by fruit flies in $\mathrm{La}$ Réunion. J Anim Ecol 75:518-526. doi:10.1111/j.13652656.2006.01072.x

Dworschak K, Blüthgen N (2010) Networks and dominance hierarchies: does interspecific aggression explain flower partitioning among stingless bees? Ecol Entomol 35: 216-225. doi:10.1111/j.1365-2311.2010.01174.x

Feener DH Jr, Orr MR, Wackford KM, Longo JM, Benson WW, Gilbert LE (2008) Geographic variation in resource dominance-discovery in Brazilian ant communities. Ecology 89:1824-1836. doi:10.1890/07-0659.1

Fellers JH (1987) Interference and exploitation in a guild of woodland ants. Ecology 68:1466-1478. doi:10.2307/1939230

Gibb H, Hochuli DF (2004) Removal experiment reveals limited effects of a behaviorally dominant species on ant assemblages. Ecology 85:648-657. doi:10.1890/030007

Gillespie RG, Roderick GK (2002) Arthropods on islands: colonization, speciation, and conservation. Annu Rev Entomol 47:595-632. doi:10.1146/annurev.ento.47.091201.145244

Gotelli NJ (2000) Null model analysis of species co-occurrence patterns. Ecology 81:2606-2621. doi:10.1890/0012-9658 (2000)081[2606:NMAOSC]2.0.CO;2

Gotelli NJ, Entsminger GL (2001) Swap and fill algorithms in null model analysis: rethinking the knight's tour. Oecologia 129:281-291. doi:10.1007/s004420100717

Gotelli NJ, Entsminger GL (2010) EcoSim: null models software for ecology. Version 7. Acquired Intelligence Inc. a Kesey-Bear. Jericho, VT 05465. http://garyentsminger. com/ecosim.htm. Last access on 24 Oct 2010
Herben T (2005) Species pool size and invasibility of island communities: a null model of sampling effects. Ecol Lett 8:909-917. doi:10.1111/j.1461-0248.2005.00790.x

Holway DA, Suarez AV, Case TJ (2002a) Role of abiotic factors in governing susceptibility to invasion: a test with Argentine ants. Ecology 83:1610-1619. doi:10.1890/00129658(2002)083[1610:ROAFIG]2.0.CO;2

Holway DA, Lach L, Suarez AV, Tsustui ND, Case TJ (2002b) The causes and consequences of ant invasions. Annu Rev Ecol Syst 33:181-233. doi:10.1146/annurev.ecolsys.33. 010802.150444

Ingram KK, Bernardello G, Cover S, Wilson EO (2006) The ants of Juan Fernández Islands: genesis of an invasive fauna. Biol Invasions 8:383-387. doi:10.1007/s10530004-3973-4

Jones TH, Blum MS, Howard RW, McDaniel CA, Fales HM, DuBois MB, Torres J (1982) Venom chemistry of ants in the genus Monomorium. J Chem Ecol 8:285-300. doi: 10.1007/BF00984024

Kenis M, Auger-Rozenberg MA, Roques A, Timms L, Péré C, Cock MJW, Settele J, Augustin S, Lopez-Vaamonde C (2009) Ecological effects of invasive alien insects. Biol Invasions 11:21-45. doi:10.1007/s10530-008-9318-y

Le Breton J (2003) Etude des interactions entre la fourmi Wasmannia auropunctata et la myrmécofaune. Comparaison d'une situation en zone d'introduction: la Nouvelle Calédonie et d'une situation en zone d'origine: la Guyane Française. PhD dissertation, Université Paul Sabatier, Toulouse

Le Breton J, Jourdan H, Chazeau J, Orivel J, Dejean A (2005) Niche opportunity and ant invasion: the case of Wasmannia auropunctata (Roger) in a New Caledonian rainforest. J Trop Ecol 21:93-98. doi:10.1017/S0266467 404002019

Le Breton J, Orivel J, Chazeau J, Dejean A (2007) Unadapted behaviour of native, dominant ant species during the colonization of an aggressive, invasive ant. Ecol Res 22:107-114. doi:10.1007/s11284-006-0014-z

Lester PJ, Abbott KL, Sarty M, Burns KC (2009) Competitive assembly of South Pacific invasive ant communities. BMC Ecology 9:3. doi:10.1186/1472-6785-9-3

Lester PJ, Stringer LD, Haywood J (2010) The role of resource dispersion in promoting the co-occurrence of dominant and subordinate ant species. Oikos 119:659-668. doi: 10.111/j.1600-0706.2009.18012.x

MacArthur RH, Wilson EO (1967) The theory of island biogeography. Princeton University Press, Princeton

Marsh AC (1985) Microclimatic factors influencing foraging patterns and success of the themophilic desert ant, Ocymyrmex barbiger. Insectes Soc 32:286-296. doi:10.1007/ BF02224917

Masciocchi M, Farji-Brener AG, Sackmann P (2010) Competition for food between the exotic wasp Vespula germanica and the native ant assemblage of NW Patagonia: evidence of biotic resistance? Biol Invasions 12:625-631. doi:10.1007/s10530-009-9469-5

McGlynn TP (1999) The worldwide transfer of ants: geographical distribution and ecological invasions. J Biogeogr 26:535-548. doi:10.1046/j.1365-2699.1999.00310.x

Meier RE (1994) Coexisting patterns and foraging behavior of introduced and native ants (Hymenoptera, Formicidae) in 
the Galapagos Islands (Ecuador). In: Williams DF (ed) Exotic ants: biology, impact, and control of introduced species. Westview Press, Boulder, pp 44-62

Menke SB, Holway DA (2006) Abiotic factors control invasion by Argentine ants at the community scale. J Anim Ecol 75:368-376. doi:10.1111/j.1365-2656.2006.01056.x

Menke SB, Fisher RN, Jetz W, Holway DA (2007) Biotic and abiotic controls of Argentine ant invasion success at local and landscape scales. Ecology 88:3164-3173. doi:10.1890/ 07-0122.1

Morrison LW (1996a) The ants (Hymenoptera: Formicidae) of Polynesia revisited: species numbers and the importance of sampling intensity. Ecography 19:73-84. doi:10.1111/j. 1600-0587.1996.tb00157.x

Morrison LW (1996b) Community organization in a recently assembled fauna: the case of Polynesian ants. Oecologia 107:243-256. doi:10.1007/BF00327909

Morrison LW (2006) The ants of small Bahamian cays. Bahamas Nat J Sci 1:27-32

O’Dowd DJ, Green PT, Lake PS (2003) Invasional meltdown on an oceanic island. Ecol Lett 6:812-817. doi:10.1046/ j.1461-0248.2003.00512.x

Parr CL (2008) Dominant ants can control assemblage species richness in a South African savanna. J Anim Ecol 77: 1191-1198. doi:10.1111/j.1365-2656.2008.01450.x

Passera L (1994) Characteristics of tramp species. In: Williams DF (ed) Exotic ants: biology, impact, and control of introduced species. Westview Press, Boulder, pp 23-43

Rao A, Vinson SB (2004) Ability of resident ants to destruct small colonies of Solenopsis invicta (Hymenoptera: Formicidae). Environ Entomol 33:587-598

Ribas CR, Schoereder JH (2002) Are all ant mosaics caused by competition? Oecologia 131:606-611. doi:10.1007/s00442002-0912-X

Rizali A, Lohman DJ, Buchori D, Prasetyo LB, Triwidodo H, Bos MM, Yamane S, Schulze CH (2010) Ant communities on small tropical islands: effects of island size and isolation are obscured by habitat disturbance and 'tramp' species. J Biogeogr 37:229-236. doi:10.1111/J.1365-2699.2009.02194.X

Room PM (1971) The relative distributions of ant species in Ghana's cocoa farms. J Anim Ecol 40:735-751

Sanders NJ, Gotelli NJ, Heller NE, Gordon DM (2003) Community disassembly by an invasive species. PNAS 100:2474-2477. doi:10.1073/pnas.0437913100

Sarty M, Abbott KL, Lester PJ (2006) Habitat complexity facilitates coexistence in a tropical ant community. Oecologia 149:465-473. doi:10.1007/s00442-006-0453-9

SAS Institute Inc (2004) SAS, 9.1.3, help and documentation. Cary, NC, USA

Savolainen R, Vepsäläinen K (1988) A competition hierarchy among boreal ants: impact on resource partitioning and community structure. Oikos 51:135-155

Savolainen R, Vepsäläinen K, Wuorenrinne H (1989) Ant assemblages in the taiga biome: testing the role of territorial wood ants. Oecologia 81:481-486. doi:10.1007/BF00378955

Seifert B (2003) The ant genus Cardiocondyla (Insecta: Hymenoptera: Formicidae) - a taxonomic revision of the C. elegans, C. bulgarica, C. batesii, C. nuda, C. shuckardi, C. stambuloffii, C. wroughtonii, C. emeryi, and C. minutior species groups. Ann Naturhist Mus Wien 104B:203-338
Simberloff DS (1969) Experimental zoogeography of islands: a model for insular colonization. Ecology 50:296-314. doi: $10.2307 / 1934857$

Simberloff D (1976) Experimental zoogeography of islands: effects of island size. Ecology 57:629-648. doi:10.2307/ 1936179

StatSoft Inc (2007). Electronic statistics textbook. StatSoft, Tulsa. WEB: http://www.statsoft.com/textbook/stathome. html

Stone L, Roberts A (1990) The checkerboard score and species distributions. Oecologia 85:74-79. doi:10.1007/BF00317345

Stringer LD, Haywood J, Lester PJ (2007) The influence of temperature and fine-scale resource distribution on resource sharing and domination in an ant community. Ecol Entomol 32:732-740. doi:10.1111/j.1365-2311.2007.00924.x

Suarez AV, Holway DA, Ward PS (2005) The role of opportunity in the unintentional introduction of nonnative ants. PNAS 102:17032-17035. doi:10.1073/pnas.0506119102

Thomas ML, Holway DA (2005) Condition-specific competition between invasive Argentine ants and Australian Iridomyrmex. J Anim Ecol 74:532-542. doi:10.1111/j.1365-2656. 2005.00952.x

von Aesch L (2006) Introduced ants in Galápagos (Floreana Island): importance of competition, coexistence and aggressive behaviors. PhD dissertation, Université Lausanne, Lausanne, Switzerland

von Aesch L, Cherix D (2005) Introduced ant species and mechanisms of competition on Floreana island (Galápagos, Ecuador) (Hymenoptera: Formicidae). Sociobiology 45:463-481

Ward D, Beggs J (2007) Coexistence, habitat patterns and the assembly of ant communities in the Yasawa Islands, Fiji. Acta Oecol 32:215-223. doi:10.1016/j.actao.2007.05.002

Ward DF, Wetterer JK (2006) Checklist of the ants of Fiji (Hymenoptera: Formicidae). In: Evenhuis NL, Bickel DJ (eds) Fiji Arthropods III. Bishop Museum Occasional Papers 85:23-47

Wetterer JK (2002) Ants of Tonga. Pacific Sci 56:125-135. doi:10.1353/psc.2002.0019

Wetterer JK (2008) Worldwide spread of the longhorn crazy ant, Paratrechina longicornis (Hymenoptera: Formicidae). Myrmecol News 11:137-149

Wetterer JK (2010) Worldwide spread of the flower ant, Monomorium floricola (Hymenoptera: Formicidae). Myrmecol News 13:19-27

Wetterer JK, Espadaler X, Wetterer AL, Aguin-Pombo D, Franquinho-Aguiar AM (2006) Long-term impact of exotic ants on the native ants of Madeira. Ecol Entomol 31:358-368. doi:10.1111/j.1365-2311.2006.00790.x

Wilson EO, Hunt GL Jr (1967) Ant fauna of Futuna and Wallis islands, stepping stones to Polynesia. Pacific Insects 9: 563-584

Wilson EO, Taylor RW (1967a) The ants of Polynesia (Hymenoptera: Formicidae). Pacific Ins Monog 14:1-109

Wilson EO, Taylor RW (1967b) An estimate of the potential evolutionary increase in species density in the Polynesian ant fauna. Evolution 21:1-10

Wittman SE, Sanders NJ, Ellison AM, Jules ES, Ratchford JS, Gotelli NJ (2010) Species interactions and thermal constraints on ant community structure. Oikos 119:551-559. doi:10.1111/j.1600-0706.2009.17792.x 